\title{
COMMUNICATION
}

\section{Polydopamine-coated open cell polyurethane foams as inexpensive, flexible yet robust catalyst support: proof of concept}

Received 00th January 20xx, Accepted 00th January 20xx

DOI: $10.1039 / x 0 x x 00000 x$
Elodie Pardieu, ${ }^{\text {ta,b }}$ Nguyet Trang Thanh Chau, ${ }^{\dagger a, b, c}$ Thierry Dintzer, $^{a}$ Thierry Romero, ${ }^{a}$ Damien

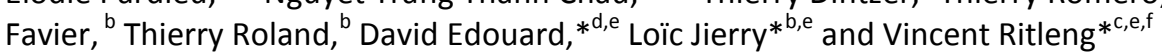

www.rsc.org/

Commercially available polyurethane open cell foams are readily coated with mussel-inspired polydopamine. The polydopamine film allows robust immobilisation of $\mathrm{TiO}_{2}$ nanoparticles at the surface of the three-dimensional material. The resulting catalyst is efficient for the photo-degradation of an azo dye, reusable and highly resistant to mechanical stress. A novel class of robust structured catalytic support, easily accessible via an inexpensive and green process, is thus described.

Continuous processes based on Structured Catalytic Supports (SCS) are widely used in industry. Indeed this type of supports allows an important surface over volume ratio, a small pressure loss, efficient mass transfers, an intimate mixing of the reagents, and an easy separation of the products from the catalyst. ${ }^{1}$ Among the variety of SCS, ceramic or metallic open cell foams are prime candidates, which fulfill all these features. $^{2-4}$ The preparation of these foams however requires several steps, including the physisorption and, when necessary, the activation of the catalytic phase (usually metallic or metal oxide particles) via expensive and energy consuming thermic treatments. ${ }^{3}$ Moreover these foams present several drawbacks inherent to their structure: (i) due to their high rigidity, micro-cracks readily appear and render them breakable, (ii) due to the presence of many randomly distributed closed cells, the reproducibility is often unpredictable, and (iii) the recovery of the catalyst adsorbed on the foam necessitates numerous chemical treatments in

Institut de Chimie et Procédé pour l'Energie, l'Environnement et la Santé, UMR CNRS 7515, Ecole européenne de Chimie, Polymères et Matériaux, Université de Strasbourg, 25 rue Becquerel, 67087 Strasbourg, France.

Institut Charles Sadron, UPR CNRS 022, 23 rue du Loess, 67034 Strasbourg,

France.E-mail: loic.jierry@ics-cnrs.unistra.fr

Laboratoire de Chimie Organométallique Appliquée, UMR CNRS 7509, Ecole européenne de Chimie, Polymères et Matériaux, Université de Strasbourg, 25 rue Becquerel, 67087 Strasbourg, France. E-mail: vritleng@unistra.fr

- Laboratoire d'Automatique et de Génie des Procédés, UMR CNRS 5007, Université de Lyon 1, 43 boulevard du 11 novembre 1918, 69622 Villeurbanne, France. Email: david.edouard@univ-lyon1.fr

e. Institut d'Etudes Avancées de l'Université de Strasbourg (USIAS), 5 allée du Général Rouvillois, 67083 Strasbourg, France.

f. Institut Universitaire de France, 103 boulevard Saint Michel, 75005 Paris, France. † These authors contributed equally to this work.

Electronic Supplementary Information (ESI) available: Details of experimenta procedures, additional characterizations, relevance of compressive loading to establish the robustness of the PDA coating. See DOI: 10.1039/x0xx00000x highly corrosive media. ${ }^{5}$ Thus, in spite of their promising architecture, metallic and ceramic open cell foams have up to now rarely been used in industrial processes.

Polyurethane foams are well known materials, and are commercially available at very low cost for a large variety of applications involving their physical and mechanical properties. ${ }^{6}$ When constituted of open cells (Fig. 1a), they are notably used for fabricating cushions, mattresses or as filters in cooker hoods, aquariums or vacuum cleaners. Moreover, they are also used as templates for the fabrication of ceramic and metallic open cell foams, and thus present similar morphological aspects and transport properties. ${ }^{3}$ Despite these physical similarities, their non-toxicity (polyurethane is commonly used as a biomaterial ${ }^{7}$ ), and their high mechanical resistance and elastic properties, ${ }^{8}$ open cell polyurethane foams (OCPUF) have never been used as SCS.

The use of OCPUF as catalytic support is hampered both by the fact that the edges' and bridges' surface is smooth and devoid of microporosity and thus does not present sufficient adherence to deposit a catalytic phase, and by the fact that traditional washcoating is incompatible with its limited stabili-

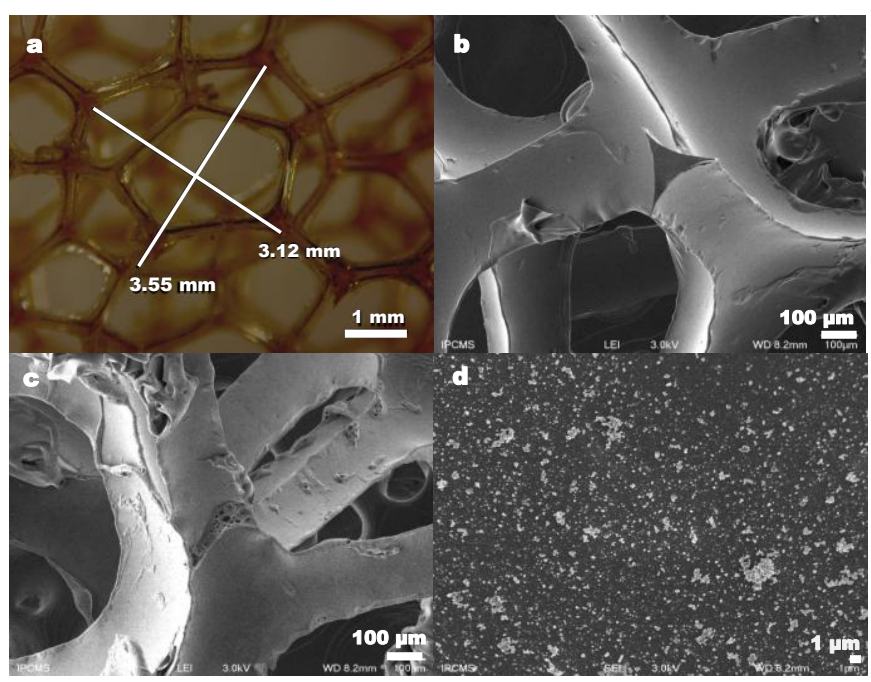

Fig.1 Optical microscopy (a) and SEM (b) images of OCPUF (1), and SEM (c,d) images of PDA@OCPUF (2) with different magnifications.

ty in temperature. ${ }^{9}$ Therefore, finding a way of grafting catalysts on the whole surface of OCPUF that is efficient, 
environmentally friendly, and compatible with its organic nature constitutes a true challenge.

The seminal work of Messersmith et al., placed polydopamine (PDA) into the spotlight as a mussel-inspired coating material that can bind to virtually all kinds of inorganic and organic support. ${ }^{10}$ In addition to these strong adherence properties, another valuable feature lies in the presence of catechol and amine functional groups that can serve both for further covalent modification with chosen molecules and for the loading of metal ions or metal oxide particles. ${ }^{11}$ PDA thus a priori possesses all the required features for allowing the use OCPUF as versatile SCS, and beyond this, for allowing functional coatings of these three-dimensional (3D) materials.

Herein, we show that OCPUF can indeed be efficiently coated with a layer of PDA ${ }^{12}$ and further functionalized with metal oxide particles. The catalytic potential of the novel PDA@OCPUF structured catalytic support is illustrated by the efficiency of immobilized $\mathrm{TiO}_{2}$ nanoparticules for the photodegradation of an azo dye, its reusability, and its high resistance to mechanical stress.

Cubic samples $\left(8 \mathrm{~cm}^{3}\right.$ ) of OCPUF (1) (20 PPI; Fig. 1a,b) were coated with PDA by simple immersion for $12 \mathrm{~h}$ at room temperature in an aqueous solution of dopamine buffered to a $\mathrm{pH}$ typical of marine environments (Fig. 2), followed by thorough washings with water. Adsorption of PDA at the surface of the resulting dark brown material (PDA@OCPUF, 2) was confirmed by X-ray photoelectron spectroscopy (XPS) (see Table S1 - ESI). In addition, low magnification scanning electron microscopy (SEM) image of $\mathbf{2}$ (Fig. 1c) revealed a coating of PDA on the whole surface of the 3D material at a macroscopic level. Higher magnification SEM image (Fig. 1d) highlighted a rough film with the presence of dispersed aggregates as typically observed on flat surfaces. ${ }^{13}$

In agreement with the known high binding abilities of the catechol groups of the PDA layer for $\mathrm{Ti}^{14}{ }^{14}$ the new SCS 2 was then functionalized with $\mathrm{TiO}_{2}$ nanoparticules (NPs) (anatase, $10 \mathrm{~nm})$ by immersion in a well-dispersed suspension $(2 \% \mathrm{w} / \mathrm{v})$ for $12 \mathrm{~h}$ at $40{ }^{\circ} \mathrm{C}$ (Fig. 2). The presence of titanium on the obtained $\mathrm{TiO}_{2} @ P D A @ O C P U F$ (3) material was confirmed by XPS (Fig. S1 - ESI). SEM micrographs combined to energy dispersive X-ray spectroscopy (EDX) (Figs. 3 \& S2 - ESI) showed that the $\mathrm{TiO}_{2}$ NPs were not uniformly distributed but were rather present as micrometric clusters randomly dispersed all over the surface of the modified 3D material. Inductively coupled plasma-optical emission spectrometry (ICP-OES) measurements on several samples of $\mathbf{3}$ revealed a mean $\mathrm{Ti}$

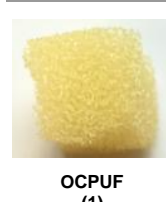

(1)

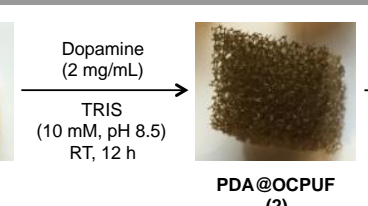

(2)

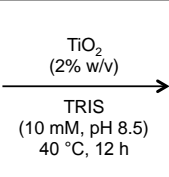

$40^{\circ} \mathrm{C}, 12 \mathrm{~h}$

$\mathrm{TiO}_{2} @ \mathrm{PD}$

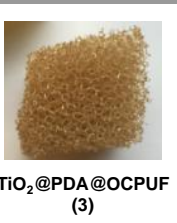

(3)
Fig. 2 Polyurethane open cell foam (OCPUF) coating with polydopamine (PDA) and functionalization with $\mathrm{TiO}_{2}$ nanoparticles
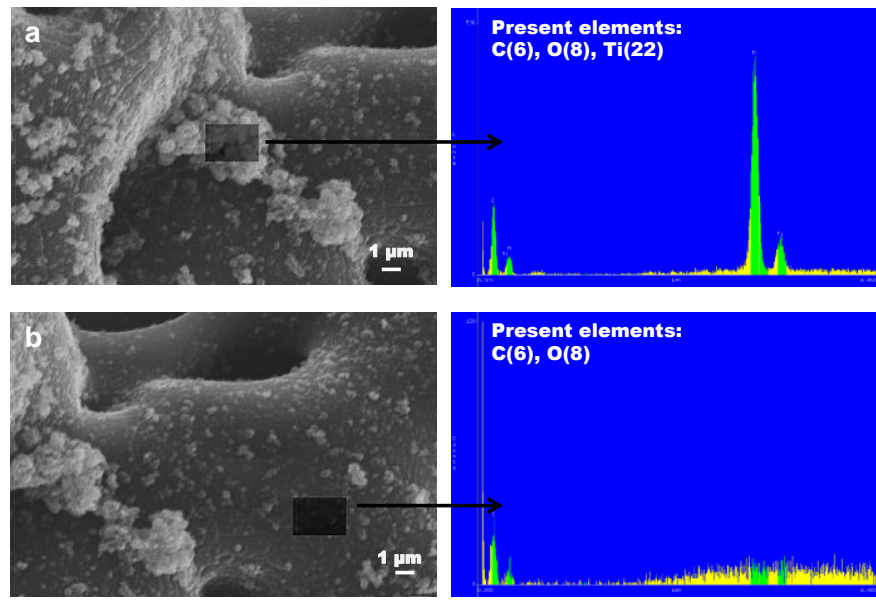

Fig. 3 SEM images (COMPO) of $\mathrm{TiO}_{2} @ P D A @ O C P U F(3)$ (left) and EDX spectra of the darkened areas (right)

content of $607 \pm 80 \mathrm{mg} / \mathrm{kg}$ (i.e. $12.7 \pm 1.7 \mathrm{mmol} / \mathrm{kg}$ ). Finally, compression tests performed on 1, $\mathbf{2}$ and $\mathbf{3}$ showed similar stress/strain responses (characterized by a typical hysteresis loop $^{8}$ ) for all three foams (Fig. 4A), thereof demonstrating that neither the PDA coating nor the further functionalization with $\mathrm{TiO}_{2}$ NPs affected the elastic properties of OCPUF 1.

The catalytic activity of the $\mathrm{TiO}_{2}$-loaded OCPUF $\mathbf{3}$ was next investigated for the photo-degradation of the noxious azo dye, acid orange 7 (AO7 - Fig. S3 - ESI), ${ }^{15}$ as a model reaction. ${ }^{16}$ For that purpose, three pieces of 3 of $0.5 \times 2 \times 2 \mathrm{~cm}$ each (ca. 150 $\mathrm{mg}$, i.e. ca. $1.91 \mu \mathrm{mol}$ of $\mathrm{TiO}_{2}$ ) were immerged in an aqueous solution of $\mathrm{AO} 7(40 \mathrm{~mL}, 28.5 \mu \mathrm{M})$, and the reaction medium was placed under UV irradiation (125 W) without stir (Fig. S4 ESI). The degradation of $\mathrm{AO7}$ was then followed by measuring
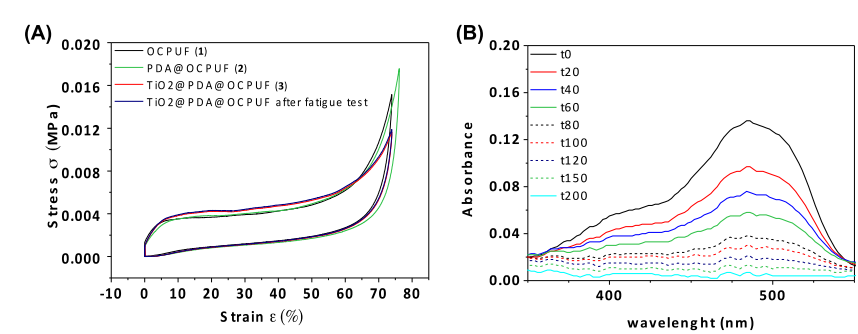

(C)

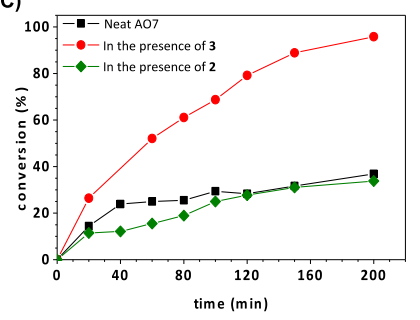

(D)

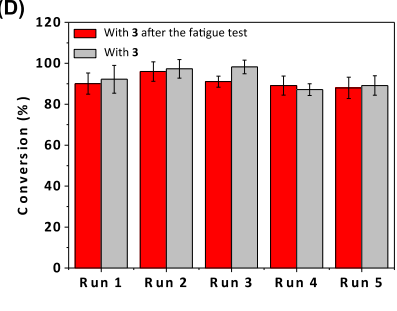

Fig. 4 (A) Stress/strain responses of $\mathbf{1}$ (black), $\mathbf{2}$ (green), as-synthesized $\mathbf{3}$ (red) and fatigue-tested 3 (blue). (B) UV-visible spectra of the AO7 solution vs. UV irradiation time ( $\mathrm{min}$ ) in the presence of 3. (C) Degradation of $A O 7$ (\%) vs. UV irradiation time (min) for neat $\mathrm{AO7}$ (black horizontal squares), $\mathrm{AO7}$ with $\mathbf{2}$ (green squares), and $\mathrm{AO7}$ with 3 (red dots); at least two runs have been performed in each case. (D) Degradation of AO7 (\%) after $200 \mathrm{~min}$ UV irradiation for runs 1 to 5 with as-synthesized 3 (grey histograms) and fatigue-tested $\mathbf{3}$ (red histograms); the average value and standard deviation of at least three experiments are represented. 
the decrease of its absorbance peak at $485 \mathrm{~nm}$ in the UV visible spectra of the reaction solution in function of the time of irradiation (Fig. 4B). Complete degradation of $\mathrm{AO} 7$ was observed after 200 min (Figs. 4B and 4C - red dots) and the resulting solution had turned colorless (Fig. S5 - ESI). In contrast, in the presence of the non- $\mathrm{TiO}_{2}$ functionalized PDA@OCPUF (2) or in the absence of foam, only ca. 35\% degradation of AO7 was observed after 200 min (Fig. 4C - black and green squares) and the solutions remained orange (Fig. S5 - ESI). Furthermore, when $\mathbf{3}$ is removed from the reaction medium, the catalytic process stops, but restarts when $\mathbf{3}$ is reimmersed in the solution (Fig. S6 - ESI). These results unambiguously demonstrate that at least some PDAembedded $\mathrm{TiO}_{2}$ NPs of $\mathbf{3}$ are accessible to the substrate, catalytically efficient, and are not released in the reaction medium. Moreover, the similar rates of AO7's degradation observed in the presence of $\mathbf{2}$ or in its absence strongly suggest that no significant adsorption of AO7 onto PDA occurs, and thus that there is no interference of such an adsorption process with the photo-degradation catalysis.

This being established, we then assessed the mechanical resistance of $\mathbf{3}$ by carrying out a fatigue test that consisted in compressing it to a strain of $75 \%$, then 5000 times to a strain of $25 \%$, and once again to a strain of $75 \%$ (Fig. S7 - ESI). Gratifyingly the stress/strain response recorded after this fatigue test was found to be similar to that recorded before (Fig 4A - red and blue curves), which shows that the flexible material $\mathbf{3}$ is highly resistant to mechanical stress.

The reusability of the mechanically stressed $\mathbf{3}$ was next examined and compared to that of as-synthesized $\mathbf{3}$. For that purpose, the PDA@OCPUF-supported catalyst was removed from the AO7 solution after each run of $200 \mathrm{~min}$, thoroughly washed with water, and then reused under the same conditions. As shown in figure 4D, the catalytic activity of mechanically stressed $\mathbf{3}$ is remarkably similar to that of assynthesized 3 and remains almost constant after five runs. Moreover, negligible amounts of titanium metal were detected from the filtrates after each run by ICP-OES $\left(1.2 \times 10^{-5}\right.$ $\left.\%<\mathrm{Ti}<4 \times 10^{-6} \%\right)$. Thus, the $\mathrm{TiO}_{2} \mathrm{NPs}$ remain catalytically active and robustly anchored at the surface of the PDA@OCPUF support even when the latter is submitted to an important mechanical stress and/or to repeated UV irradiations. This later observation is in perfect agreement with the well-known free radical scavenging properties of PDA that make it useful as a UV protective layer on polymer materials. ${ }^{17}$

In summary, polydopamine has been used to coat macroscopic 3D structures in the form of flexible polyurethane open cell foams. Thanks to its remarkable adherence properties, the mussel-inspired coating allows to consider polyurethane open cell foams as a new structured catalytic support as illustrated by the robust immobilization of $\mathrm{TiO}_{2} \mathrm{NPs}$, and its successful use for the photo-degradation of AO7. Both, the obtained PDA@OCPUF support and $\mathrm{TiO}_{2} @ P D A @ O C P U F$ catalytic material remarkably conserve the flexibility, high mechanical resistance, and morphological characteristics (and thus the transport properties) of the non-coated OCPUF. Moreover, this new catalytic tool proved to be reusable at least five times, and did not leach even under rough conditions.

This pioneering work opens the way to other uses of PDA@OCPUF as structured catalytic support. In particular, the presence of catechol and amine functional groups opens the possibility to covalently modify it with well-chosen molecules, ${ }^{10,11}$ and therefore perhaps to use it as support for organo- and/or organo-metallic catalysts. Moreover, the ability of polydopamine to reduce some metal ions ${ }^{18}$ may allow to circumvent the impossibility to activate immobilized metallic salts or metal oxides by classical reduction methods at high temperature $^{9,19}$ (in reason of the organic nature of OCPUF), and therefore allow its use as support for metal(0)-based active phase. These attractive perspectives are currently under study in our laboratories.

\section{Acknowledgements}

We are grateful to the University of Strasbourg Institute for Advanced Study (USIAS) for financial support (2012 fellowship to $D E, L$ and $V R$ ).

\section{Notes and references}

1 J. J. W. Bakker, W. J. Groendijk, K. M. de Lathouder, F. Kapteijn, J. A. Moulijn, M. T. Kreutzer and S. A. Wallin, Ind. Eng. Chem. Res., 2007, 46, 8574.

2 G. Groppi, E. Tronconi, Chem. Eng. Sci., 2000, 55, 2161; L. Giani, G. Groppi, Ind. Eng. Chem. Res., 2005, 44, 4993.

3 J. T. Richardson, Y. Peng, D. Remue, Appl. Catal. A, 2000, 204, 19.

4 M. Lacroix, P. Nguyen, D. Schweich, C. Pham Huu, S. SavinPoncet, D. Edouard, Chem. Eng. Sci., 2007, 62, 3259.

5 M. Lacroix, L. Dreibine, B. de Tymowski, F. Vigneron, D. Edouard, D. Bégin, P. Nguyen, C. Pham, S. Savin-Poncet, F. Luck, M.-J. Ledoux, C. Pham Huu, Appl. Catal. A, 2011, 397, 62.

6 H.-W. Engels, H.-G. Pirkl, R. Albers, R. W. Albach, J. Krause, A. Hoffmann, H. Casselmann, J. Dormish, Angew. Chem. Int. Ed., 2013, 52, 9422.

7 A. Rahimi, A. Mashak, Plastics, Rubber and Composites, 2013 42, 223.

8 L. Gong, S. Kyriakides, W.-Y. Jang, Int. J. Solids Struct., 2005, 42, 1355.

9 B. Lapčíková, L. Lapčík, Jr. J. Polym. Mater. 2011, 28, 353.

10 H. Lee, S. M. Dellatore, W. M. Miller, P. B. Messersmith, Science, 2007, 318, 426.

11 E. Faure, C. Falentin-Daudré, C. Jérôme, J. Lyskawa, D. Fournier, P. Woisel, C. Detrembleur, Prog. Polym. Sci. 2013, 38, 236.

12 For PDA coating of acid-etched PU sponges for filtration purposes, see: S. Seok, S. Shin, T. J. Lee, J.-M. Jeong, M. Yang, D. H. Kim, J. Y. Park, S. J. Lee, B. G. Choi, K. G. Lee, ACS Appl. Mat. Interfaces, 2015, 7, 4699.

13 R. A. Zangmeister, T. A. Morris, M. J. Tarlov, Langmuir, 2013, 29, 8619.

14 H. Lee, N. F. Scherer, P. B. Messersmith, Proc. Natl. Acad. Sci. USA, 2006, 203, 12999.

15 Azo dyes such as $\mathrm{AO}$ are major water contaminant coming mainly from the textile industry: K. P. Sharma, S. Sharma, S. Sharma, P. K. Singh, S. Kumar, R. Grover, P.K. Sharma, Chemosphere, 2007, 69, 48; S. M. A. G. Ulson de Souza, E. Forgiarini, A. A. Ulson de Souza, J. Hazard. Mat., 2007, 147, 
1073; T. Robinson, G. McMullan, R. Marchant, P. Nigam, Bioressource Technol. 2001, 77, 247.

16 For recent examples of $\mathrm{TiO}_{2}$-based catalysts for the photodegradation of AO7, see: J. Lei, Y. Chen, L. Wang, Y. Liu, J. Zhang, J. Mater. Sci., 2015, 50, 3467; S. H. Hsieh, W. J. Chen, C. T. Wu, Appl. Surf. Sci., 2015, 340, 9; S. Garcia-Segura, S. Dosta, J. M. Guilemany, E. Brillas, Appl. Catal. B, 2013, 132133, 142; X. Chen, W. Wang, H. Xiao, C. Hong, F. Zhu, Y. Yao, Z. Xue, Chem. Eng. J., 2012, 193-194, 290 ; M. Zlamal, J. Krysa, J. Jirkovsky, Catal. Lett., 2009, 133, 160.

17 M. d'Ischia, A. Napolitano, V. Ball, C.-T. Chen, M. J. Buehler, Acc. Chem. Res. 2014, 47, 3541.

18 Y. Liu, K. Ai, L. Lu, Chem. Rev. 2014, 114, 5057.

19 S. Luidold, H. Antrekowitsch, JOM, 2007, 59, 20. 